UCID- 19706

\title{
MASTER
}

\author{
HUMAN FACTORS ENGINEERING \\ CONTROL-ROOM-DESIGN REVIEW/AUDIT REPORT: \\ PALO VEROE NUCLEAR GENEHATIHG STATION, \\ ARIZONA PUBLIC SERVICE COMPANY \\ Jack W. Savage \\ David A. Lappa \\ Lawrence Livermore National Laboratory
}

Octoter 9, 1981

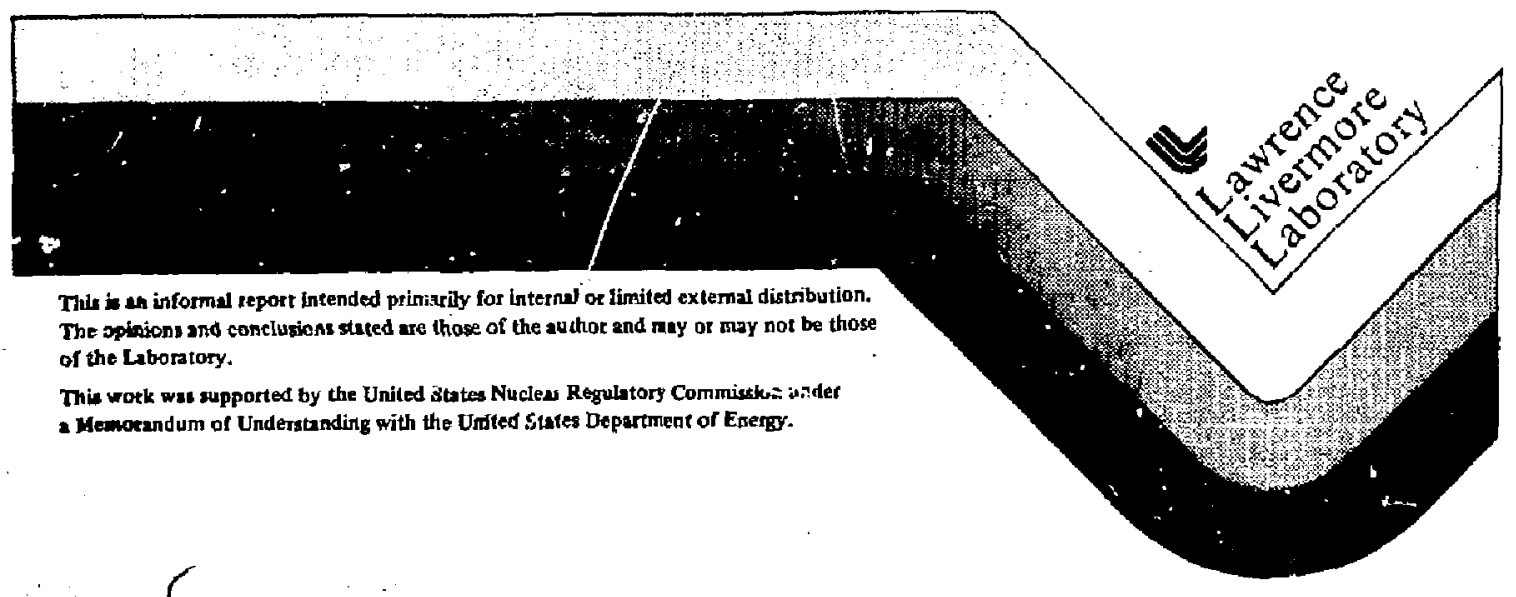

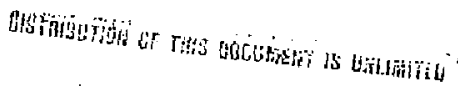




\author{
HUMAN FACTORS ENEINEERING \\ CONTROL-ROOM-DESIGN REVIEW/AUDIT REPORT: \\ PALO YERDE NUCLEAR GENERATING STATION, \\ ARIZONA PUBLIC SERVICE COMPANY
}

\title{
Introduction
}

A human actors engineering design review of the Palo Verde control room simulator was performed at the site on September 15 through September 77 , 1981. The report was prepared on the basis of the Human Factors Engineering Branch (HFEB) audit of the applicant's Preliminary Design Assessment (PDA) and the human factors engineering design review performed at the site. This design review was carried out by a team from the HireB, Division of Human Factors Safety. The review team was assisted by human factors consultants frni, BioTechnology, Inc. (Falls Church, Virginia) and from Lawrence Livermore Notional Laboratory (University of California), Livermore, California.

Observed human factors design dizcrepancies were given a priority rating of 1,2 or 3 (high, moderate or Jow), besed on the increased potential for operator error and the possible consequerices of that error. Priority rating 1 and 2 discrepancies should be corrected prior to issuance of an operating license. Priority rating 3 discrepancies should be evaluated and proposed actions reported as part of the long-term design review in accordance with the guidance provided in NUREG-0700. Note that some priority 3 ratings include a superscript 7 (i.e., $3^{1}$ ). Since priority 3 discrepancies involve simple corrective actions relative to the potential for improving operator performance, they should be corrected prior to issuance of an operating license.

The following sections are numbered to conform to the guidelines of NUREG-0700 and sumarize the team's observations of the control room design and layout and of the control room operators' interface with the control room environment.

A list of the human factors strengths observed in the Palo Verde controi room sirulator is given at the end of the nine major sections of this report. This list includes those features that the review team felt enhanced the operator interface with the control room simuiator. Finally, a list of those items that could not be evaluated is presented. The condition of construction or installation of these items at the $t$ ime of the site visit was not sufficiently finalized to permit review.

It is expected that the plait control rooms will be made to exactly match the simulator and that the licensee's commitments to correct discrepancies incluoed in this report will apply to both.

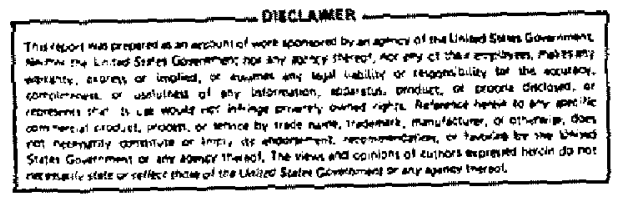


1. CONTROL. ROOM WORKSPACE

\begin{tabular}{|c|c|c|c|c|}
\hline PHOTO ID & REVIEWER & $\begin{array}{l}\text { PR IORITV } \\
\text { RATINE }\end{array}$ & FIMDING & \\
\hline & $J D, U S$ & 3 & $7^{*}$ & $\begin{array}{l}\text { The control room boukshelves are inadequate. } \\
(056 \mathrm{C})\end{array}$ \\
\hline $51, \mathrm{H9}$ & $\mathrm{JD}, \mathrm{JS}$ & 2 & $2 *$ & $\begin{array}{l}\text { Glare is a problem for most displays on all } \\
\text { of the panels. It is worst on the "C" } \\
\text { surfaces, depending on viewing angle. } \\
\text { (See Fig. 1 on page } 3 \text { for the meaning of } \\
\text { "A", "B", "C, and "D" surfaces) } \\
(049 C)(064 C)(700 B)(1018)(103 C)\end{array}$ \\
\hline \multirow[t]{2}{*}{$\$ 2$} & 30,35 & 1 & $3^{\star}$ & $\begin{array}{l}\text { Glare on CMC switch surfaces hinders } \\
\text { "light-on" determination. This is more } \\
\text { apparent on the "C" surfaces. A matte } \\
\text { surface might not be as effective a solution } \\
\text { as brighter lights. } \\
\text { Example: (Panel BOE) } \\
\text { a) ESF SWGRA/EQPT Room switch } \\
\text { (OOBC) }\end{array}$ \\
\hline & $\mathrm{JD}, \mathrm{JS}$ & $3^{1}$ & $4 *$ & $\begin{array}{l}\text { The concrete control room floor is not } \\
\text { carpeted, which will lead to earl ier fatigue } \\
\text { during long periods of standing by the } \\
\text { operators. } \\
\text { (068B) }\end{array}$ \\
\hline
\end{tabular}

Note: Throughout the report,

* Discrepancy also noted in Arizona Public Service (APS) Palo Verde Nuclear Generating Station Control Room Human Factors Study.

- The numbers and letters in parentheses are the IDs from the APS study.

- The numbers in parentheses not followed by letters are the ID numbers of Human Engineering Discrepancies (HEDs) identified by the HFEB audit team.

- Numbers in parentheses preceded by CLD are APS Check Tist Discrepancy numbers. 


\section{PALO VERDE}

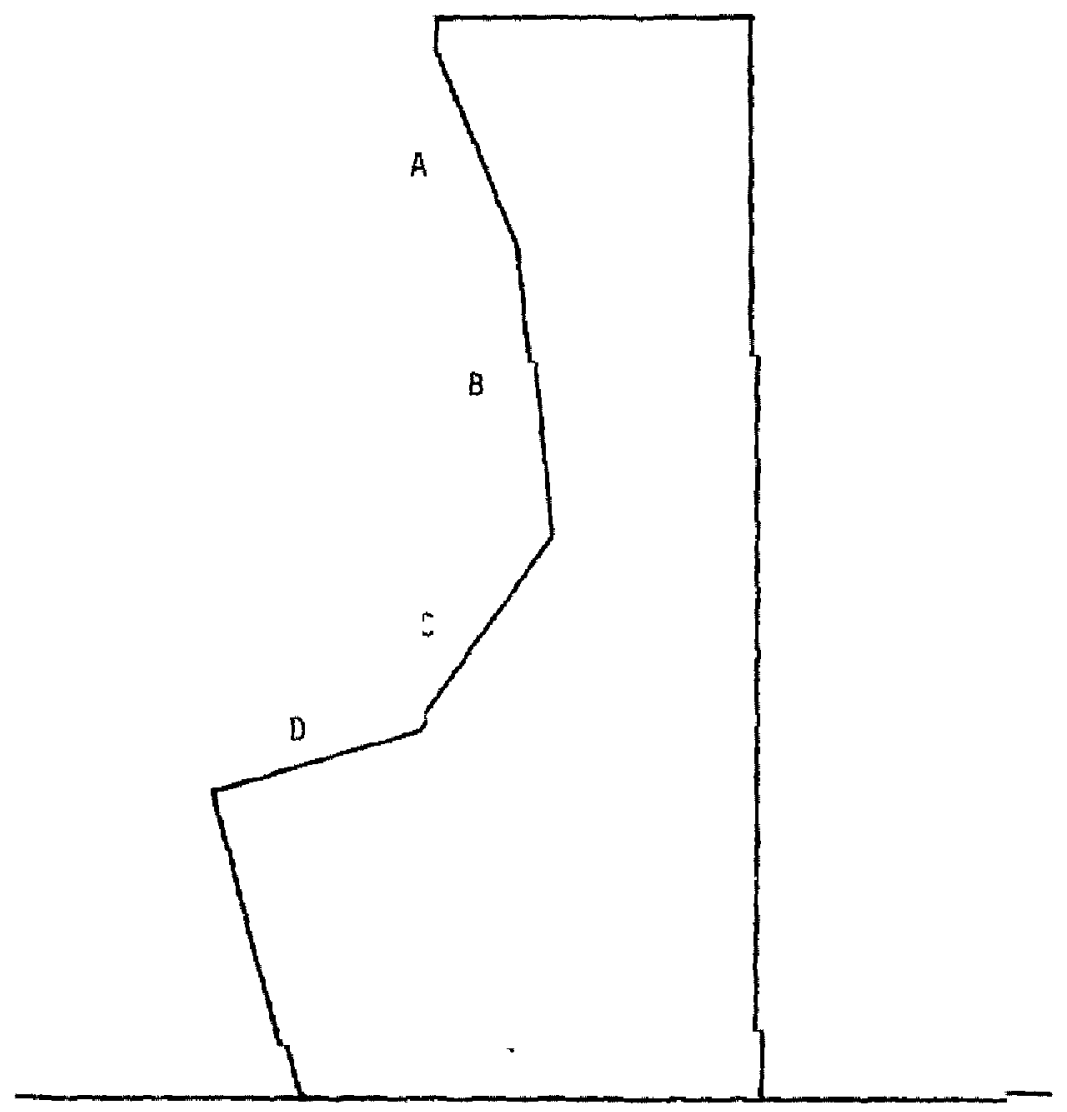

FIG. 1. Identification letters of the four control board surfaces. 
2. COMHUNICATIONS

PHOTO ID REVIEWER PRIORITY

RR, RS 11 Instructions are not provided for the use of

RR, RS 112 Procedures have not been established for handling incomins communications at night or during emergencies.

(003)

RR,RS $\quad 1 \quad 3$ The switching mechanism for the

conventionaliy powered telephone system is not programmed to give the control room automatic priority access to the switching sys tem.

(004)

$R 75$

$R R, R S$

1

$4 \star$

The short telephone cords prevent total panel coverage by the operators. The problem is particularly acute on the CVCS and Condensate System panels.

(0678)

RR, RS $\quad 3^{7}$

$R R, R S$

1

$R R, R S$

5 No address labels and/or index are supplied for sound-powered phone jacks in the contro? room.

6 EMI noise susceptibility tests have not been conducted to denonstrate that low-level analog or digital equipment is not affected by the frequency bands used by walkietaikies.

7 Procedures have not been developed to provide unambiguous identification of the person speaking on the walkie-talkie when there are two or more parties on a channel operating at separate locations. (006) 
3. ANNUNCIATOR WARNING SYSTEMS

\section{PRIORITY}

PHOTO ID REVIEWER RATING FINDING

RR,RS 1 i* $\begin{aligned} & \text { The Annunciator System has several } \\ & \text { discrepancies. }\end{aligned}$

$R R, \cap S$

3

$R R, R S$

2

RR, RS

3

R7

KN,RS
$R R, R S$
RR,RS

$R R, R S$

1

$R R, R S$

1

RR, RS

2 Some alarms require the operator to direct an auxiliary operator to a given plant location to obtain specific imiormation. Example: (Pane1 807)

a) Rad haste System Troubie Tile

3 Some annunciators (e.g., some systems on Panel B07) have inguts from more than one plant parameter, but an alarm printout capability is not provided to identify the alarm source.

4 The Turbine Generator System First-0ut annunciator panel on Panel 804 should be located with the turbine/generator controls on Panel B05.

(032)

The Turbine Generator System First-Out annunciators on Panel BO4 have tiles with sma11 print font.

6 The nature of the annunciator auditory signals could, in some cases, cause irritation or a startled reaction.

7 A logical alarm prioritization has not been applied to allow operators to differentiate the most serious alarms from less important ones.

8 Auditory signals do not enable the operator to identify the work station location or system associated with the alarm. (034)

9 More than 5 separate frequencies have been used for audible signal coding. The present use of eleven urique frequencies is excessive.

10* The Condensate Low Vacuum alarm should be located on Panel $\mathrm{BO} 7$ and not on Panel $\mathrm{BOS}$.

(0958) 


\section{ANNUNCIATOR WARNING SYSTEMS}

PHOTO ID REVIEWER PRIORITY

\begin{tabular}{|c|c|c|c|}
\hline$R R, R S$ & 2 & $17 *$ & $\begin{array}{l}\text { The Plant Monitoring System Trouble alarm } \\
\text { should be located on Panel BO4 and not on } \\
\text { Panel Bol. } \\
\text { (094C) }\end{array}$ \\
\hline RR, RS & 1 & $12 *$ & $\begin{array}{l}\text { There are no Main Generator Trip alarms near } \\
\text { the associated controls on Pane } 1 \mathrm{~B} 06 .(045 \mathrm{~B})\end{array}$ \\
\hline$R R, R S$ & $3^{1}$ & 13 & $\begin{array}{l}\text { Annunciator panels are not identified by } \\
\text { labels above the panels. } \\
\text { (038) }\end{array}$ \\
\hline$R R, R S$ & ] & 14 & $\begin{array}{l}\text { No procedure exists to ensure that a legend } \\
\text { tile is replaced in the correct location } \\
\text { after it has been removed for lamp } \\
\text { replacement. }\end{array}$ \\
\hline$R R, R S$ & 1 & $15 *$ & $\begin{array}{l}\text { Reaching annunciators to replace lamps poses } \\
\text { a safety problem. (004A) }\end{array}$ \\
\hline$R R, R S$ & 2 & 16 & $\begin{array}{l}\text { Annunciator tiles do not illuminate and burn } \\
\text { steadily in case of a flasher failure. (040) }\end{array}$ \\
\hline RR,RS & $3^{1}$ & 17 & $\begin{array}{l}\text { The vertical and horizontal axes of } \\
\text { annunciator panels are not labeled with } \\
\text { a Iphanunerics for easy coordinate designation } \\
\text { of a particular visual tile. }\end{array}$ \\
\hline
\end{tabular}

RR,RS 318 The number of alarm tiles exceeds the suggested limit of 50 tiles per matrix.

RR, RS i

19 Cues for prompt identification of an out of service annunciator are not provided. Rather, periodic testing is required to determine whether an annunciator is out of service.

20 The "Seal $0 \mathrm{O} 1 / \mathrm{H}_{2}$ Uiff Press Lo" tije on Panel B06 should be reworded to ind icate whether the turbine or the generator is being referred to.

21* Inconsistent terminology exists between a] arms and controls for Generator Seal 0 il on Panel B06. 
3. ANNUNCIATOR WARNING SYSTEMS

\begin{tabular}{|c|c|c|c|c|}
\hline PHOTO ID & REVIEWER & $\begin{array}{l}\text { PRIORITY } \\
\text { RATING }\end{array}$ & FINDING & \\
\hline R5 & $R R, R S$ & $3^{l}$ & $22 *$ & 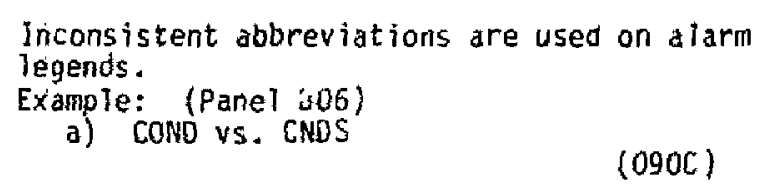 \\
\hline R4 & $R R, R S$ & $3^{7}$ & $23 *$ & $\begin{array}{l}\text { Inconsistent alarm legends exist for Linear } \\
\text { Power Density on Panel } \mathrm{BO5} \text {. } \\
(085 \mathrm{C})\end{array}$ \\
\hline R3 & $R R, R S$ & 1 & $24 *$ & $\begin{array}{l}\text { On Panel BO4, the annunciator legend is } \\
\text { incorrect for T-AVG and T-REF temperature } \\
\text { deviation and for RC SYS TRBL. } \\
\text { (OBIA) }\end{array}$ \\
\hline $\mathrm{R} 2$ & $R R, R S$ & $3^{7}$ & $25 *$ & $\begin{array}{l}\text { Inconsistent terminology exists between } \mathrm{H}_{2} \\
\text { Train alarms and associated control labeis on } \\
\text { Panel B02. } \\
\text { (073C) }\end{array}$ \\
\hline \multirow[t]{2}{*}{ RI } & $R R, R S$ & $3^{1}$ & $26^{\star}$ & $\begin{array}{l}\text { On Panel B06, inconsistent terminology exists } \\
\text { on the alarm window for Header Pressure, } \\
\text { (i.e., the word "system" in "Condensate Pump } \\
\text { Hdr Press Syst Trouble" should be deleted.) } \\
\text { (047C) }\end{array}$ \\
\hline & $\mathrm{RR}, \mathrm{RS}$ & 3 & 27 & $\begin{array}{l}\text { Some alarms on Panel } 807 \text { refer the operator } \\
\text { to other, more detailed annunciator panels } \\
\text { located outs ide the primary operating area. } \\
\text { Example: } \\
\text { a) Rad Waste and fuel Pool. }\end{array}$ \\
\hline \multirow[t]{2}{*}{$\begin{array}{l}\text { R9, RI0, } \\
\text { RIT }\end{array}$} & $R R, R S$ & 2 & 28 & $\begin{array}{l}\text { Some tile legends do not address specific } \\
\text { conditions. For example, one alarm is used } \\
\text { for Hi-Low and Temperature-Pressure. } \\
\text { (045) }\end{array}$ \\
\hline & $R R, R S$ & 1 & 29 & $\begin{array}{l}\text { Administrative procedures do not exist which } \\
\text { require and contro? the periodic testing of } \\
\text { annunciators. }\end{array}$ \\
\hline $\mathrm{R} 12$ & $R R, R S$ & $3^{7}$ & 30 & $\begin{array}{l}\text { Annunicator response controls have not been } \\
\text { coded for easy recognition. }\end{array}$ \\
\hline
\end{tabular}




\section{CONTROLS}

\section{PHOTO ID REVIEWER RATING FINDING}

DL

510

$J 0, J S$

3

57

JD,JS

$\mathrm{JD}, \mathrm{JS}$

$\mathrm{JD}, \mathrm{JS}$

S3

L29

S31

$\mathrm{JD}, \mathrm{JS}$

$3^{1}$
1

The manual activation circuitry for the Panel B05 ESFAS system is based on selected two out of four logic which is different from the auto ESFAS which operates on any two out of four Togic.

(150)

2 When GE switch handles are allowed to spring back from "Stop," the position indicator flag may go to "red" instead of staying on "green." Example: (Panel B06)

a) Switch FWPT A Turning Gear R01A

3* There is a problem distinguishing among the five types of Foxboro controllers and disp lays.

4* On Panel B05, the Manual Reactor Trip controls lack protection covers.

5* On Pane ?s B03, B04, B06, and B07, several controls are tuo close to the pane? edge, increasing the likelihood of accidental activation.

6* The protection covers on some of the setpoint reset controls on Pane? 305 can be left open.

7 There is an inconsistent use of black and amber bezel color coding on CMC switches. Example: (Panel B03)

a) Reactor Drain Tank Outlet Isolation Valve

b) Makeup Supply to Reactor Urain Tank Valve

(072)

54

$\mathrm{JD}, \mathrm{JS}$

1
$8^{*}$ The red/green color coding of the Generator Field Excitation pushbuttons is reversed on Panel B06. (0358) 
4. CONTROLS

\begin{tabular}{|c|c|c|c|c|}
\hline PHOTO 1D & REVIEWER & $\begin{array}{l}\text { PRIORITY } \\
\text { RATING }\end{array}$ & FINOING & \\
\hline \multirow[t]{2}{*}{ \$5 } & 30,35 & 31 & $9 *$ & $\begin{array}{l}\text { It is possibie to interchange legend screens } \\
\text { on pushhutton legend controls if more than } \\
\text { one is removed at a time. } \\
\text { Examp le: (Panel } 807 \text { ) } \\
\text { a) Cooling Tower fan controi panel } \\
\text { (O50C) }\end{array}$ \\
\hline & 30,35 & $3^{1}$ & $10^{*}$ & $\begin{array}{l}\text { The Panel } \mathrm{BO3} \text { keyswitch for Letdown Control } \\
\text { Valve Bypass (CHM-H5-526) requires keyteeth } \\
\text { pointing up, which violates the control room } \\
\text { convention. } \\
\text { (059B) }\end{array}$ \\
\hline \$8 & $30, J S$ & $3^{1}$ & $1 i^{*}$ & $\begin{array}{l}\text { On Pane } \mathrm{BO2} \text {, there is too strong a resistance } \\
\text { for keyswitches requiring activation for long } \\
\text { periods. These keys have stall key heaos, } \\
\text { aggravating the situation. } \\
\text { (1136) }\end{array}$ \\
\hline 530 & 30,35 & $3^{1}$ & 12 & $\begin{array}{l}\text { Some CMC switch position indicators point } \\
\text { between switch positions. } \\
\text { Example: (Panei B03) } \\
\text { a) Pre-Holdup lox In let Bypass Selector } \\
\text { (071) }\end{array}$ \\
\hline
\end{tabular}

$511,437 \quad 30, \mathrm{US}, \mathrm{RH} \quad 3^{1}$

$13^{*}$ Control position is not visible during use of the fluclear Cooling Water HX control on Pane] B07. The pointer on the knob will be covered by the operator's hand. Also, position indications are obscured by the knob. $(C L D-4.024)(053)$

$R R$

There is an excessive use of keylock switches in the control room.

(074) 


\section{DISPLAYS}

\begin{tabular}{|c|c|c|c|c|}
\hline PHOTO IO & REVIEWER & $\begin{array}{l}\text { PR IORITY } \\
\text { RATING }\end{array}$ & FINDING & \\
\hline L 21 & DL & 2 & $T^{\star}$ & $\begin{array}{l}\text { There s no valve position indication for the } \\
\text { Demineralizer Differential Pressure Control } \\
\text { Bypass Valve on Panel B05. }\end{array}$ \\
\hline
\end{tabular}

$$
\text { H38 }
$$

RH

2

$\mathrm{H} 35, \mathrm{~L} 74 \quad \mathrm{RH}$

3

$H 6, H 7$

$\mathrm{RH}$

1

2

On Panel B05, channels $A, B, C$ and $D$ have Caiculator Select controls for CEAC. however, this capability exists only on thannels $B$ and c.

3 On Panel $B 05$, operators have been given the ability to calibrate the "actual" power level indicator using a helipot control which appears on the benchboard. The "actual" level appears on the same Foxboro display as the "sensed" power level, which varies with time. Inadvertent use of the control can ca:'se false power level readings if the caijbration is changed.

(101)

4 The loss of one of the two signal trains causes the status of 2 loops to be indeterminari: in the High Pressure Safety Injection flow indication on Panel BO2.

(077A)

L8

DL

2

$5 *$

On Pane1 B06, there is inadequate Steam Generator Level indication during manual, auxiliary and ma in feedwater contral.

(089A)

Lา0

$\mathrm{DL}, \mathrm{RH}$

3

6* Foxboro recorders do not provide good resolution over a short time range because of a slow recording speea.

$\begin{array}{ll}\text { L5 } & \text { DL } \\ H 36 & \text { RH }\end{array}$

RH

$7 *$ There is no averload indication on the ammeters for large pumps.

(1068)

2

1

8* On Pane1 B05, there is inadequate indication of safety system status (i.e., SIAS, MSIS, (IAS, etc.).

(029A)

9* There is a need for a wide-range pressure and

leve] indication near the pressurizer controls on Panel B03.

(0178) 


\section{IISPLAYS}

\section{PHOTO ID REVIEWER RATING FINDING}

LI3 RH $3 \quad$ The large size of the power factor meters
found on panel go6, is not consistent with
their importance.
(092C)

$5=7$

11 There is an unnecessary, redundant indication for the Refueling Water Tank Level (CHN-LI-700) on Panel B03.
HiO RH $\quad 3$
12* There is a lack of intermediate valve position indication for jog-open valves on Panel BO6. valve position is known only when vaive is fuily open or fully closed.

$\lfloor 6, H] T \quad$ DL, RH $\quad 1$
13* $M$ arge number of Foxboro meters and recorders have a 0 - 100 (i.e., "z) scale instead of an engineering unit scale. Example: (Pane 7 B05)
The SG level indicators are scaled 0 - 100\% for both the narrow and wide $\begin{array}{ll}\text { ronge. } & (0838)(11 i c)\end{array}$
L16 DL $\quad 2 \quad 14$ The plastic faces of the Foxboro displays seem to scratch and become obscured eas ily. They also produce excessive s?are. 127$\}$
$\$ 12 \quad 35$
i5 The blue switch position indizator lights, on CMC switches, are not c leariy visible in the ambient control room light. Example: (Fanel B07)
a) Containment Purge Mode Selector

$\begin{array}{lll}H 42 & R H & 3 \\ L 2 & \text { DL } & 1 \\ L 12 & D L & 3\end{array}$

16 Sonie Foxboro display scales incorporate leading decimais whicn are difficult to notice, leading to possible misreading of the scale numerals.

17* Un all Foxboro displays in the control room, the engineering units of $\mathrm{pa}$, ameters being measured are not given.

18 On many displays, e.g., the small ammeter displays, the graduation size is too sma?l and the scale labeling is hard to reat. 


\section{DISPLAYS}

\begin{tabular}{|c|c|c|c|c|}
\hline PHOTO ID & REVIEWER & $\begin{array}{l}\text { PRIORITY } \\
\text { RATING }\end{array}$ & FINDING & \\
\hline & $R H$ & $3^{1}$ & 19 & $\begin{array}{l}\text { Foxboro meters having major, intermediate, } \\
\text { and minor graduations do not differentiate } \\
\text { intermediate and minor by using different } \\
\text { index lengths. Instead, index mark thicknes } \\
\text { is used, and is difficult to discriminate. } \\
\text { (514) }\end{array}$ \\
\hline $\mathrm{L} 13, \mathrm{HI} 3$ & $\mathrm{RH}, \mathrm{OL}$ & 3 & 20 & $\begin{array}{l}\text { There is a poor scale progression on some } \\
\text { meters. } \\
\text { Examples: } \\
\text { a) LOOP IA T-HOT / LOOP 2A T-HOT } \\
\text { b) LOOP IA T-COLD / LOOP } 2 A T-C O L D \\
(515)\end{array}$ \\
\hline L11 & DL & 3 & 2) & $\begin{array}{l}\text { Foxboro display sca?e units are sometimes } \\
\text { inconsistent in their use of decimal points. } \\
\text { For example, some have 100, 200, etc. while } \\
\text { others use. } 1 \mathrm{~K}, \text {. 2K etc. } \\
\text { Example: (Panel BO6) } \\
\text { a) AFW DUMP B DISCH PRESS }\end{array}$ \\
\hline
\end{tabular}

a) AFW DUMP B DISCH PRESS

$\mathrm{H4}, \mathrm{H} 74: \quad \mathrm{RH}$

Red/green coloring is used to denote open/closed, following the industry convention. However, red/green are also used for other coding besides valve and breaker positions.

H12

RH

$3^{1}$

3]

$\mathrm{H} 12$

$\mathrm{RH}$

H4]

$\mathrm{RH}$

3

$3^{1}$

214

\begin{abstract}
$\mathrm{DL}$
\end{abstract}
RH
23* The Core Protection Calculator indicator lights on Panel BO5 have incorrect color coding.

(1160)

24* The Plant Protection System relay status lights on Panel B05 are incorrectly colored. (0878)

25 Foxboro displays have a parallax prob?em, especially, those located on the lower part of the benchboard.

26 Zone mark ings have not been used on meters to show the operational implications of various readings (e.g. "Danger Range").

(523)

27* The scales in the foxboro displays are loosely fitted, allowing incorrect positioning. 
5. DISPLAYS

\section{PHOTO ID REVIEWER RATING FINDING}

L1 OL 2 28* There is a lack of lamp redundancy in the CMC switches.

$(002 C)$

$\angle 3 \quad D L \quad 2$

$\mathrm{HI}, \mathrm{H}$ ?

RH

2

DL.

2

L3

aL

2

RH

2

$\mathrm{L} 7, \mathrm{HB}$

DL

2

$\llcorner 38$

$D L$
29* There is a lack of lamp redundancy on the Generex panel on Pane1 806.

$(032 C)$

$30^{*}$ There is little distinction between lamp failure and status change of CMC switches. There are possible conditions when no light will be on, or when more than one shouid be on.

(OOTC)

$31^{*}$ There is no lamp test capability on CMC switches. (003C)

32* Lamp removal must be done from the back of the generex panel on Panel B06. (C33C)

33* Green light intensity is used to distinguish faulted from normal status on the Electric Bus Panel on Panel BOi. However, thr two intensities are not discernible unless one witnesses the change in intensity as it happens.

34* The Plant Protection System controls on Panel B05 are illuminated wher they are in the OFF position, in violation of the convention used throughout the control room. (088B)

35 On Pane? B04, the control rod full insertion indicator array uses a 'Tight of ' condition to signal faijure to fully insert. An unlit indicator coula be difficult to find among a field of lit tiles during a reactor scram. However, this approach proves to be sat isfactory during a dropped rod situation. In this case, all tiles are unlit, except that for the dropped rod, which is lit. (075) 
5. DISPLAYS

PHOTO 1D REVIEWER PRIORITY

$\begin{array}{ll}\mathrm{H} 3, \mathrm{H4}, \mathrm{H5} & \mathrm{RH}, \mathrm{DL} \\ \mathrm{S6} & \mathrm{JD}, \mathrm{JS}\end{array}$

H12

LT5

S6

$\mathrm{JD}, \mathrm{JS}$

DL

3

2
36* There is a general problem which allows

legend screens for both indicator lights and backlit switches to be interchanged. Examples:

a) Electric Bus Panel on Panel 1801

b) SESS Panel on Panel 802

c) CEDM Panel on Panel B04

d) Reactor Power Cutback System on Pane1 B04.

e) EHr, Control Panel MTN-A-09 $(005 C) ;(014 C) ;(021 C) ;(063 C)$

37 The Plant Protection System relay status lights are illuminated to indicate availatility. A given light goes out when the related plant Protection system is not available.

38 The low light intensity of some indicators makes them difficult to read.

39* There is a lack of distinction between legeno lights and backlit switches.

Example:

EHC Control Pane? MTN-A-09

L4
40* Typing-over of data accurs on the multipoint trend recorders on Pane 107. 


PHOTO IO REVIEWER PRJORITY

\begin{tabular}{|c|c|c|c|c|}
\hline$H 40$ & RH & 2 & $1^{\star}$ & $\begin{array}{l}\text { The logic for selecting the correct pairs of } \\
\text { the manual reactor trip controls on Panel } \mathrm{BOS} \\
\text { is not clearly indicated on the poard. } \\
\text { (030Aj) }\end{array}$ \\
\hline L17 & $\mathrm{DL}$ & $3^{]}$ & $2^{*}$ & $\begin{array}{l}\text { There are missing labels on the Electric Bus } \\
\text { mimic on Panel Bol. } \\
(017 B)\end{array}$ \\
\hline L18 & DL & $3^{1}$ & $3^{*}$ & $\begin{array}{l}\text { There are missing iabels on the controls for } \\
\text { the CR ESSENTIAL AHU FAN DAMPERS on Pane } 1 \text { BO2. } \\
(015 A)\end{array}$ \\
\hline$H 16$ & RH & $3^{1}$ & $4^{*}$ & $\begin{array}{l}\text { Labels are either missing or non-descriptive } \\
\text { on the FW \& SR Systems Board on Fane } B 06 \\
\end{array}$ \\
\hline$L 22$ & $D L$ & $3^{3}$ & $5 *$ & $\begin{array}{l}\text { There a:e missing labels on the Main Steaming } \\
\text { Rate suitches on Panel } 806 \text {. } \\
(046 \mathrm{~B})\end{array}$ \\
\hline H2C & RH & $3 T$ & $6 *$ & $\begin{array}{l}\text { There are onsing labels on the RAS ACTIVATION } \\
\text { controls on Panel B05. } \\
\text { (084A) }\end{array}$ \\
\hline 514 & 30,75 & $3^{7}$ & 7 & $\begin{array}{l}\text { There are no labels on the pushbuttons on } \\
\text { Panel B06. } \\
\text { (055) }\end{array}$ \\
\hline$\$ 24$ & $\mathrm{JD}, \mathrm{uS}$ & $3^{1}$ & i & $\begin{array}{l}\text { There are no labels on the indicator lights } \\
\text { on Panel } 807 . \\
(064)\end{array}$ \\
\hline$L 30$ & DI. & 31 & 3 & $\begin{array}{l}\text { On Panel 805, the SG Flow indicator is not } \\
\text { labeled. } \\
(134)\end{array}$ \\
\hline$H 25,516$ & $\mathrm{RH}, \mathrm{JD}, \mathrm{JS}$ & 37 & 10 & $\begin{array}{l}\text { None of the panels/consoles in the ma in } \\
\text { control room use a hierarchical iabeling } \\
\text { scheme. All labeling is at individual } \\
\text { component level, except for subpaneis for } \\
\text { some systems (e.g., SESS; Plant Protection } \\
\text { System; etc.) }\end{array}$ \\
\hline $\mathrm{H} 12, \mathrm{H}_{2} \mathrm{I}$ & RH & $3^{1}$ & $11 *$ & $\begin{array}{l}\text { The label locations for the four ONBR/LPD } \\
\text { calculatirs on Panel B05 are not cons istent. } \\
\text { Trains } A \text { and } B \text { are labeled below while trains } \\
C \text { and } D \text { are labeled above. } \\
\text { (092C) }\end{array}$ \\
\hline
\end{tabular}


PHOTO ID REVIEHER PRIORITY

$\mathrm{H29}, \mathrm{H30} \quad \mathrm{RH} \quad 3^{3}$

H31

RH

$3^{1}$

H23

120

Hi3

$D L$

$3^{1}$

L9

DL

$3^{7}$

124

DL

1

$\mathrm{H} 24$

$\mathrm{RH}$

$\$ 15$

JD, US

$3^{1}$

428

RH

3)

$\lfloor 31$

DL

3

12 Some component labels are not placed above or in the best proximity to the equipment they identify. In genera?, display labels appear below the displays, while controt labels are above.

(103)

13 A temporary label has been taped to the pane? to explain the control positions for the Nuclear cooling Water $4 X$ which appears on Panel BO7.

14* On the vertical panels, the Foxboro aisplays obscure their own labeling.

15* There is an incorrect label on the keactor Coolant Pump 78 control.

16 There is inadequate labeling on the LOOP IA T-HUT / LOOP 2A T-HOT indicator OFi Panel BO6. It currently reads:

LOOP I T-HOT / LOOP 2 T-HOT.

17* Ambiguous labeling appears on 311 duatindicator Fnxboro dispiays. Displays have side-by-side vertical scales, while the 1 abe 15 are placed one above the other. Plart convention is, the upper label refers to the left hand scale while the lower label refers to the right hand scale.

18* There is an incorrect label on the 0iese? Generator start-stop switch panel BOl.

19* Incorrect labeling is used for the alarm ackniwledge button on the Radiation Monitor Terminal.

20 On Pane? 806, the MSIV control labels are insufficientiy descriptive.

21 On Panel 806 , trend recorders are not labeleo as being designatable.

(637)

22 Redundant but incomplete leseling is used on the Manual Reactor Trip controis on Panet 805. There are two "trip" labeis on each, and nowhere is the trip channel specifically stated. 
6. LABELS AND LOCATION AIDS

\begin{tabular}{|c|c|c|c|c|}
\hline PHOTO ID & REVIEWER & $\begin{array}{c}\text { PRIORITY } \\
\text { RATING }\end{array}$ & FINDING & \\
\hline \multirow[t]{2}{*}{$137, \mathrm{H} 46$} & $\mathrm{RH}, \mathrm{OL}$ & $3^{]}$ & 23 & $\begin{array}{l}\text { On Panel } 804, \text { labels for Reactor Coolant pump } \\
\text { seal pressure and temperature are inconsister } \\
\text { and do not provide adequate irformation. } \\
\text { They do not indicate "pressure" and } \\
\text { "temperature" as app] icable, and whether thes } \\
\text { are inlet or outlet sampling points. (116) }\end{array}$ \\
\hline & $D L$ & 1 & $24^{*}$ & $\begin{array}{l}\text { On panel } 802 \text {, the SESS Panel and related } \\
\text { board items have incons istent labeling. } \\
(076 \mathrm{~A})\end{array}$ \\
\hline$\llcorner 35$ & $D L$ & 31 & 25 & $\begin{array}{l}\text { Poor labeling is used on the LP Heater Train } \\
\text { controls, i.e., TRAIN-OUTLET V.s. TRAIN } \\
\text { INLET. }\end{array}$ \\
\hline $\mathrm{H} 43, \mathrm{H} 44$ & RH & 2 & 26 & 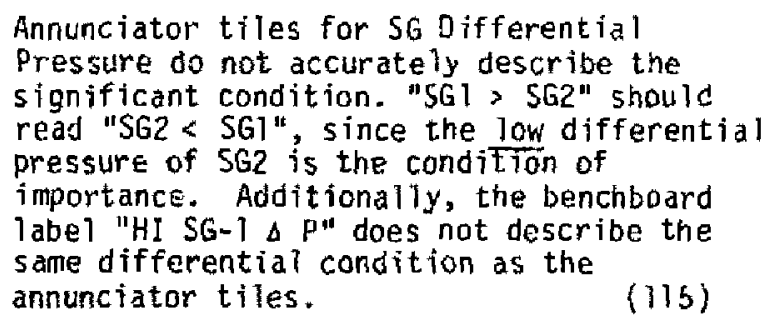 \\
\hline $\mathrm{H} 26$ & RH & $3^{7}$ & $27^{*}$ & $\begin{array}{l}\text { There are more than } 3 \text { lines of text on } \\
\text { several switch and indicator legends. }\{114 \mathrm{~L}\rangle\end{array}$ \\
\hline L 36 & $\mathrm{DL}$ & $3^{l}$ & 28 & $\begin{array}{l}\text { Inconsistent abbreviations are used in sonte } \\
\text { locations. } \\
\text { Examples: (on PaneT BO5) } \\
\text { a) COND = Condenser } \\
\text { COND = CondenSate } \\
\text { b) COND POLISHING CCMIN OUTLT ULV } \\
\text { CONDENSATE POLISHING DEMIN INLT VLV } \\
\text { CONDENSATE POLISHING DEMIN DIFF } \\
\text { PRESS CONT }\end{array}$ \\
\hline
\end{tabular}

$13 \quad$ OL 3

29 There is a general problem with the selection and usage of abbreviations in the labeling throughout the control room. Abbreviations are not consistently applied and are sometimes not clear in the ir meaning. Example:

a) The use of cowD for Condenser and CNDS for Condensate. These choices do not uniquely ident if $y$ the namies involved. 
6. LABELS AND LOCATION AIDS

\begin{tabular}{|c|c|c|c|c|}
\hline PHOTO ID & REVIEWER & $\begin{array}{c}\text { PRIORITY } \\
\text { RATING }\end{array}$ & FINDING & \\
\hline 530 & RS & $3^{1}$ & 30 & $\begin{array}{l}\text { There are inconsistent abbreviations on the } \\
\text { component label and the switch legend for the } \\
\text { Pre-Holdup Iox Inlet Bypass Selector an } \\
\text { Pane? B03. }\end{array}$ \\
\hline L41 & $D L$ & $3^{1}$ & 31 & $\begin{array}{l}\text { The Audio Range Selector on Panel } 804 \text { has no } \\
\text { position Tabeling to indicate the } \\
\text { multiplication factor being chosen. (L4T) }\end{array}$ \\
\hline$H 45, \$ 26$ & $R H, J D, J S$ & $3^{1}$ & 32 & $\begin{array}{l}\text { The position labeling on some iajswitches is } \\
\text { misleading. } \\
\text { Examples: } \\
\text { a) The position label "LOCKED NORMAL" } \\
\text { refers to the normal position of the } \\
\text { key and has no meaning with respect to } \\
\text { the equipment being controlled. } \\
\text { b) When key is in "LOCKED" position, } \\
\text { operator does not know whether it is } \\
\text { locked open or locked closed. }\end{array}$ \\
\hline
\end{tabular}
H36 RH $\quad 3^{l} \quad 33$ Most ESFAS rotary controis are jog-...pe, while some (AFAS-1, AFAS-2) have two discrete positions. This distinction is not apparent from the control appearance.

H36

RH

$3 i$

H28

OL

$3^{1}$

H18

RH

$3^{1}$

$\llcorner 25$

$\mathrm{DL}$

1

H19

RH
$3^{1}$
34 Manua? ESFAS switches have no position indications or direction of movement indicators.

35 The procedure for labeling the designatable trend recorder is to handwrite the current designation on an adjoining metal plate with a grease pen. This is not very legible.

[53])

36* There is an illegible Tabel for the CWP/Bypass switch on Panel B04. (066)

37* Label calor is incorrect for the "HOT LEG INJECTION B FLOW" on Panel 802.

38* On Pane1 B03, the mimic line to the charging pumps used during loss of power is inissing from the CVCS mimic.

(0794) 


\begin{tabular}{|c|c|c|c|c|}
\hline PHOTO ID & REVIEWER & $\begin{array}{l}\text { PRIORITY } \\
\text { RATING }\end{array}$ & FIND ING & \\
\hline $425, \mathrm{~S} 25$ & $\mathrm{RH}, \mathrm{JD}, \mathrm{JS}$ & $3^{l}$ & $39 *$ & $\begin{array}{l}\text { There is a lack of demarcation of all major } \\
\text { systems on most of the panels. } \\
\text { (112A) }\end{array}$ \\
\hline $\mathrm{H} 17$ & RH & $3^{l}$ & $40^{\star}$ & $\begin{array}{l}\text { Ineffectual multi-colored strips appear on } \\
\text { some boards. } \\
(052 A)\end{array}$ \\
\hline $\begin{array}{l}\mathrm{H} 25, \mathrm{H} 32 \\
\mathrm{H} 33, \mathrm{H} 34 \\
\$ 28\end{array}$ & $R H, J D, J S$ & 3 & 41 & $\begin{array}{l}\text { There is a general inconsistency in the } \\
\text { use of color coding in the control } \\
\text { room. } \\
\text { Examples: } \\
\text { a) Mimic colors are not consistently } \\
\text { applied, and sometimes use the same } \\
\text { colors as in the train/channel color } \\
\text { coding on the same panel. } \\
\text { b) The use of both blue and white as an } \\
\text { override indication on some vaive } \\
\text { controls. }\end{array}$ \\
\hline
\end{tabular}

\begin{tabular}{|c|c|c|c|c|}
\hline L 19 & $D L$ & 2 & $42^{\star}$ & $\begin{array}{l}\text { On Panel BO3, there is no clear minic } \\
\text { indication where the flow to and from the } \\
\text { reactor occurs. Easically, there is a need } \\
\text { for a clear minic terminator. } \\
(020 \mathrm{C})\end{array}$ \\
\hline 427 & RH & $3^{1}$ & $43^{*}$ & $\begin{array}{l}\text { There are missing mimic lines on the Electric } \\
\text { Bus mimic on Panel BOI. } \\
\text { (IISC) }\end{array}$ \\
\hline 520 & $\mathrm{JD}, \mathrm{JS}$ & $3^{i}$ & 44 & $\begin{array}{l}\text { The Electric Bus mimic on Panel BOl does not } \\
\text { identify Units } 2 \text { \& } 3 \text { on buses } 505 \text { and } 506 \text {. } \\
(060)\end{array}$ \\
\hline H35 & $\mathrm{RH}$ & $3^{1}$ & 45 & $\begin{array}{l}\text { Directiond } 1 \text { arrows are missing from some } \\
\text { mimics. (The absence of arrows from the } \\
\text { Electric Bus minic is acceptable.) (107) }\end{array}$ \\
\hline$S 23$ & $30, \mathrm{JS}$ & $3^{1}$ & 46 & $\begin{array}{l}\text { Motor Operated Disconnect (M0) switch } \\
\text { controls on Panel Bol are too far away from } \\
\text { the assaciated Moo on the mimic. (063) }\end{array}$ \\
\hline$\$ 27$ & JD, JS & 37 & 47 & $\begin{array}{l}\text { On Panel B01, the circuit Breaker control } \\
\text { switch is not labeled to identify the } \\
\text { breaker, and is located in the mimic as } \\
\text { though it is part of the white-bus when it is } \\
\text { not. }\end{array}$ \\
\hline 522 & 30.35 & 31 & 48 & $\begin{array}{l}\text { There are several breakers on Panel } 801 \text { which } \\
\text { are not incorporated into a mimic. }(062)\end{array}$ \\
\hline
\end{tabular}




\begin{tabular}{|c|c|c|c|c|}
\hline PHOTO ID & REVIEWER & $\begin{array}{l}\text { PRIDRITY } \\
\text { RATING }\end{array}$ & FINDING & \\
\hline & RR, RS & 3 & 1 & $\begin{array}{l}\text { The computer system does not contain a } \\
\text { sequential file of operator entries which are } \\
\text { available upon operator request. (048) }\end{array}$ \\
\hline & $R R, R S$ & 3 & 2 & $\begin{array}{l}\text { On Panel B05, the numeric-only key configur- } \\
\text { ation is not the same in all cases. For } \\
\text { example, the Core Protection Calculator } \\
\text { keyboard is calculator sty? and the Core } \\
\text { Monitoring Computer keyboard is telephone } \\
\text { style. }\end{array}$ \\
\hline \multirow[t]{6}{*}{ R14 } & $R R, R S$ & 3 & 3 & $\begin{array}{l}\text { Communication Corisole (I-J-SQN-RR75) control } \\
\text { room keyboards contain keys which are not } \\
\text { used by operators. (It may be that the } \\
\text { keyboard is not used at all.) }\end{array}$ \\
\hline & $R R, R S$ & 3 & 4 & $\begin{array}{l}\text { The Radiation Monitoring Printer } \\
\text { mult ip le-mode keyboard utilizes the same keys } \\
\text { for both alphanumerics and functions by using } \\
\text { "shift" keys. } \\
\text { (008) }\end{array}$ \\
\hline & RF, RS & 1 & 5 & $\begin{array}{l}\text { Computer system operating procedures and } \\
\text { contingency proceoures have not been } \\
\text { develaped. } \\
\text { (oog) }\end{array}$ \\
\hline & $R R, R S$ & 2 & 6 & $\begin{array}{l}\text { Data point aduresses are not cross-indexed by } \\
\text { program name, system/subsystem, and } \\
\text { functional group. (010) }\end{array}$ \\
\hline & $R R, R S$ & 2 & $7^{*}$ & $\begin{array}{l}\text { There is glare on the CRT screens } \\
(053 C)(065 C)\end{array}$ \\
\hline & $\mathrm{RR}, \mathrm{RS}$ & 2 & 8 & $\begin{array}{l}\text { Disturbing flicker is evident on the CRT on } \\
\text { Panel Bol. } \\
(011)\end{array}$ \\
\hline \multirow[t]{2}{*}{$\mathrm{R} 13$} & RR, RS & 3 & 9 & $\begin{array}{l}\text { CRT fonts use variable stroke widths such } \\
\text { that the vertical strokes of the characters } \\
\text { are narrower than the horizontal strokes. } \\
\text { (047) }\end{array}$ \\
\hline & $R R, R S$ & 3 & $10^{\star}$ & $\begin{array}{l}\text { There are missing labels in the CRT data } \\
\text { displays. } \\
\text { (054C) }\end{array}$ \\
\hline
\end{tabular}




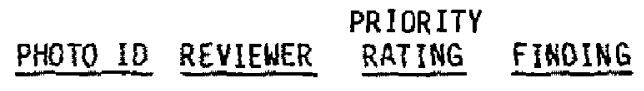

\begin{tabular}{|c|c|c|c|}
\hline$R R, R S$ & 3 & ד* & $\begin{array}{l}\text { Labe } 1 \text { highlighting is lacking in the CRT data } \\
\text { displays. } \\
\text { (055C) }\end{array}$ \\
\hline$R R, R S$ & 2 & 12 & $\begin{array}{l}\text { Error messages on the CRT displays do not } \\
\text { contain instructions to the operator } \\
\text { regarding required corrective action. (0T3) }\end{array}$ \\
\hline$R R, R S$ & 2 & 13 & $\begin{array}{l}\text { When the process computer system requires the } \\
\text { operator to standby, periosic feedback is not } \\
\text { provided to the operator to indicate norma } 1 \\
\text { system operation and the reason for the } \\
\text { delay. }\end{array}$ \\
\hline
\end{tabular}

RR,RS $3 \quad 14$ Color use on the CRT is not consistent with other color coding in the control room. (0T5)

RR,RS $3 \quad 15$ Color coding used in CRT displays does rot conform to guidelines. (076)

RR,RS 216 Printers do not have a printing capabiity of at least 300 lines per minute.

RR,RS I 17 Printed material does not have an adequate contrast ratio due to the ribbon condition. (019)

$\mathrm{RR}, \mathrm{RS} \quad 2$

18 The operatur has no capability to request printouts by alara group (e.g., system, subsystem, component). (020)

19 Computer printouts of alarms print siowly and contain too much extraneous information.

(CLD $11-032)^{+}$ + This APS Checklist Discrepancy (CLD) was not included in the Audit Report sent
to APS, but was cited in the HFEB ingut to the SER. 
8. PANEL LAYOUT

PHOTO ID REVIEWER PRIORITY

$\mathrm{DL}, \mathrm{JD}, \mathrm{JS} \quad 1$

1* On Pane1 B04, the Reactor coolant Pump 1A control is in close proximity to the Backup Heater Bank A3I - A35. Handies are similar in shape, leading to a potential operator error and reactor trip.

(096B)

H37

$\mathrm{RH}$

2

On PaneT B05, the layout sequence of the Reactor Protection Pretrip/Trip indicators is poor. Related indicators are not grouped together.

Examples:

a) Reactor Power

b) Pressurizer Pressure

c) Steam Generator Leve?

JD,JS

2

]$^{*}$

There is an inconsistent mode select sequence for the MSR switches on Pane 1 806. (093C)

L8 DL

4

On Pane 1 BO6 the $S G 1$ and $S G 2$ wide range steam generator Tevel indicators are not consistentiy located with respect to the narrow range indicators.

(LOS)

L.28

DL

3

5

There is a lack of symmetry between the RPS control switches and the corresponding status lights on the lower benchboard on Panel B05.

139

DL

3

6

On Panel B04, the Reactor Coolant Pump 2A (2B) DP displays are separated by the Core $2 \mathrm{H}$ DP display.

(L39)

$1-34$

DL

7 Mirror imaging is used in the layout of related controls for Condensate Pumps $A, B \& C$ as well as for the Condenser controls/displays on Panel 805 .

513

$$
\text { JD, JS }
$$

3

8

Panel B06 has a hybrid component layout with mixed mirror image and replicated controls and displays.

(055)

RR, RS

s* The layout of the SESS Panel poes not conform with the Tayout of Pane T BO2.

(078C) 
8. PANEL LAYOUT

PHOTO ID REVIEWER PRIORITY

DT

2

10 Some differences exist between the designs of the simulator and the Unit 1 control room. (See page 26, item 1)

439

RH

$3^{1}$

11 Key tags for keyswitches obscure nearby labels and other contro1s/displays. (112)

$519 \quad 30,45$

2

$12^{*}$ There is possible interference among the controls on the benchboard of Panel B07 due to their closeness at the intersection of surfaces "C" and "D."

(097C)

L42

DL

3

13 On Panel $\mathrm{BO} 4$ there is inadequate functional grouping of the Rod Motion Control indicator lights. (L42) 


\section{CONTROL-DISPLAY INTEGRATION}

\section{PHOTO ID REVIEWER PRIORITY}

S17

$$
\mathrm{JD}, \mathrm{JS}
$$

2

H47 RH

H37

RH

3

$+46$

RH

3

578

518

$\mathrm{JD}, \mathrm{JS}$

3
JD.JS

3

1 About 16 annunciator tiles located on Panel $\mathrm{B} 01$, belong on the Panel $\mathrm{B} 06$ board section where they will be used to signal corrective action to be controlied from Panel 806.

Example:

a) Main Generator $\mathrm{V} / \mathrm{Hz}$

b) Main Generator Excitation,

c) Under Frequency Negative Sequence Pretrip

2 On Panel B04, the five automatic reactor regulation control rod motion denand indicators can be lit in confliat with a manual mode of operation that the operator has selected.

(119)

3 Trip indicaturs for High Log-Power and Low Pzr Press should be located in closer proximity to the High Log-Fower Bypass and Low Par Press Bypass controis.

4 In most instances on 804 , each of 4 pumps has a separate set of Foxboro meters. However, on the RCP inlet and outlet, common temperature meters are used, wherein, the left bar of the meter is for pump $1 A$ and the $r$ ight ber of the same meter is for pump $1 \mathrm{~B}$. The same is true for $2 A$ and $2 B$.

$5 *$

On Panel B01, the Diesel tienerator Synchroscopes are more than nine feet from the circuit breaker controls.

On Panel B01, the Incoming Voltmeters associated with the Diese 7 Generators are located too far from the circuit breaker controls.

(070) 
HUMAN FACTORS STRENGTHS OBSERVED

3. The mobile procedure cart with procedures attached is a good way to make procedures conveniently available. (Fhoto 59 ).

2. . The "diamond" orientation of the control switches in the cucs mimic enhances the operator's understanoing of the functions being executed. (Photo \$29).

3. The angled CRT mounting enhances display visibility for the operators.

4. The low height of the CRT cabinets on the sit down console provides easy viewing of other control board sections.

5. The 5 degree slape on controi board surface "E" enhances the usability of the controls and displays.

E. The turn-to-start/push-to-stop feature of some valve motion controls frees the operator to perform other functions as compared to controls that require turn-and-hold-to-activate.

7. Generally, the layout and grouping of systems, subsystems and components is clean ano uncluttered.

8. There are few instances of long, unb. oken rows of similar displays.

9. The number of alarm windows is not excessive.

10. A zero reading is clearly differentiated from a falled-meter status on Foxboro displays.

11. Mimics have been used to enhance the aperators undersicanding of systems.

12. Equipment labeis are generaliy legible.

3. First-out annunciator paneis for reactor trip and turbine trip will identify the initiating events for the operators.

14. Safety systems status is indicated by the SESS Faner. 
The following items were unavailable for review in whole or in part:

1. A detailed comparison of the simulator with the Unit 1 control room could not be performed to identify all differences that might exist.

2. General Layout

- Document organization and storage

- Spare parts, operating expendables and: tools

- Supervisor access

- Mon-essential personnel iccess

3. Emergency Equipment

- Operator protective equipment

- Fire, radiation and rescue equipment

- Emergency equipment storage

4. Environment

- Temperature and humidity

- Ventilation

- Emergency lighting

- Auditory environment

- Personal storage

- Ambience and comfort

5. The absence of documents made it impossible to evaluate consistency of procedure terminology with labels, displays, abbreviations, or document indexing and cross-referencing.

6. Due to the existing state of the system, it was not possible to adequately evaluate the CRT displays for content and data presentation format.

7. Lack of actual emergency gear prevented the evaluation of the operation of controls while wearing or using the emergency gear, or the availability of $f$ ace masks with diaphragms capable of transmitting speech.

8. The actual discernability and reliability of audio signals above ambient noise could not be measured.

9. The capability of complete internal and external communications during emergencies (i.e., paging at the remote shutdown pane 1 andior direct communication with back panels, shift supervisor's office, etc.) could not be evaluated. 
10. Since only Panel 806 had color-shaded background panel sections, it was not possible to evaluate the effectiveness of the use of shading colors to identify groups of functionally related controls and displays throughout the contral room.

11. The proposed Plant Protection System logic alarm box on Pane 1 Bos could not be evaluated because it is not yet installed.

12. It was not possible to evaluate the out-of-service and temporary labeling systems because they had not been developed.

13. It was not possible to evaluate the following instrumentation systems because they were not available:

a.) In-core thermocouple instrumentation displays

b.) Sub-cooling monitor instrumentation displays 
Listed below are the deleted discrepancies, followed by the reason for deietion.

HED NO.

DISCREPANCY

DBOA

Labels on CVCS charging pumps on Panel 803 imply incorrect operation.

Reason for deletion: The labels are correct for the present configuration.

$122 A$

The CMC switches used for jog-valve control have uncomfortable knobs.

Reason for deletion: There is no need to hold knobs longer than 20 seconds.

$060 \mathrm{~B}$

NORMAL position labels are missing on ali jog keyswitches.

Reason for deletion: The NORMAL Tabei nas no meaning for the center position for the jog keyswitches and is misleading.

$013 \mathrm{C}$

There are sharp edges on bookstops on Panels 802 and B07.

Reason for deletion: No discrepancy found.

$058 \mathrm{C}$

There is a lack of operator understanding of the control board design.

Reason for deletion: Training considerations are outside the scope of the HFEB review.

069C

On Panel BO2, there is glare on the SESS Panel which hinders a light-on determination.

Reason for deletion: The lights are easily apparent when lit.

$117 \mathrm{C}$

The Generator Ground Volimeter is poorly located.

Reason for deletion: This voltmeter has been moved. 
The following HFEB audit team finding relates to procedures and operator training. It will be referred to the Procedures and Test Review Branch for further consideration:

On Pane 1 B05, operator fatigue/error, leading to inadvertent reactor trip, may result from the procedure for reducing the LO PZR PRESS and LO SG PRESS setpoints during shutdown. The procedure must be repeated several times and for each of the 4 channels on the Reactor Protection System. 
$1-1$ H1

$1-2$ H2

$1-3$ H3

$1-4 \quad H 3$

$1-5 \quad H 4$

$1-6 \quad 45$

$1-7 \quad H 6$

$1-8 \quad H 6$

1-9 H7

1-10 H8

$1-11+9$

$1-1249$

$1-13$ H10

1-14 HIT

$1+15$ H12

$1+16$ H12

$1-17$ H13

1-18 H14

$1-19+15$

$1-20+15$

$1-21$ H76

$1-22 \mathrm{HI} 7$

$7-23$ H78

$1-24 \mathrm{H} 19$

$1-25$ H2O

$1-2 E$ H2O

$\begin{array}{lll}1-27 & H 2 ?\end{array}$

7-28 H21

$1-29+22$

$1-30$ H:3

$1-31$ H.3

1-32 H24

$7-33$ H25

$1-34$ H25

$1-35$ H26

$1-36+427$

1-37 H28

$7-38$ H29

$1-39+129$
"Auto" not lit when "Start" is 1 it

"Auto" not lit when "Start" is lit

Screen interchange possibility

Lamp interchange possibility

Controls/displays mixed

Controls/displays mixed

High Pressure Safety Injection Flow indicators

High Pressure Safety Injection Flow indicators

High Pressure Safety Injection Flow indicators

Incorrect color coding

No giare

G7are

Lack of position indication (undetented positions)

Lack of parameter engineering units on recorders

Improper color usage

Improper color usage

Poor scale progression

Violation of color coding convention

Calibration helipot

Bisplay associated with hel ipot control

Missing or non-descriptive labeling

color striping

Obscured type

Nimic missing

Mimic missing

Mimic missing

Inconsistent label positioning

Incons istent label positioning

No label

Obscured labeling

Obscured labeling

Incorrect labeling

No hierarch jcal yabeling

No hierarchical labeling

Mare than 3 lines of texto

Missing mimic

Incorrect labe]

Label locations

Label locations 
1-40 H5O Poor label locations

1-47 H37 Control position labeling obscured by hand and handle

$1-42$ H31 Control position labeling obscured by hand and handle

?-43 H31 Contral position labe? ing obscured by hand and handle

1-44 H32 Inconsistency in colar coding

1-45 H32 Inconsistency in color coding

1-46 H33 inconsistency in color coding

1-47 H33 Inconsistency in color cading

1-48 $\mathrm{H34}$ Inconsistency in color coofing

1-49 $\mathrm{H} 35$ No directional arrows

1-50 H35 No directional arrows

1-5T H36 No pasition indicators

1-52 $\mathrm{H3} 7$ Lack of grouping

1-53 H38 Useless cantrols

1-54 H38 Use less controls

T-55 H39 Key obscures label/controls

I-56 H40 Incons istent logic on RPS

1-57 H4l Parallax on Foxboro displays

1-58 H4 1 Parallax on Foxboro displays

1-59 H47 Parallax on Foxboro displays

1-60 H4l Parallax on Foxbo*o displays

1-61 H42 Poor scale labeling (use of leading decimal points)

1-62 H42 Poor scale labeling (use of leading decimal points)

I-63 H43 Poor Tabeling

$1-64$ H44 Poor labeling

1-65 H45 Mis Teading labeling

7-66 H46 Displays used in conman

1-67 H46 Displays used in common

1-68 H47 Display can be improperiy illuminated (not shown lit)

1-69 447 Display can be improperly il luminated (not shown lit)

1-70 L1 Lack of bulb redundancy

I-7I L2 No parameter engineering units displayed

$1-72$ l3 No lamp redundancy

1-73 L4 Overprinting on trend recorders

1-74 L4 Overprinting on tread recorders

$1-75$ L5 No overload amperes indication

$1-76$ i5 No overjoad amperes indication

1-77 $L 6$ No scale units. Percent is used

1-78 L7 Controls illuminated when in 'OFF' position (not shown lit)

1-79 L8 Need wide range indicator

$1-80$ LB Need wide range indicator

T-8i L9 Ambiguous labeling

1-82 t.10 Too litt?e detail on trend recorder (only 1 in./hr)

l-83 Ll1 Scales not consistent

1-84 L)1 Scales not consistent

1-85 Lll Scales not consistent 
1-86 L12 Graduation (whole meter actually) size is too small

i-87 L12 Graduation (whole meter actually) size is too small

1-88 L13 Poor scale progression

1-89 L14 Lack of zone markings

1-90 L15 Light intensity too low

1-91 L15 Light intensity too low

1-92 L16 Plastic covers obscured by scratches, etc.

i-93 Li7 No labels on mimic lines

1-94 L18 Missing labels

7-95 L18 Missing labeis

1-96 L19 Lack of mimic terminators

1-97 L20 Incorrect label

1-98 L20 Incorrect labe 1

1-99 L21 No value position indication

1-100 L21 No value position indication

1-101 L22 Missing Tabels (on/off)

1-102 L23 Missing NORMAL Tabel

1-103 L24 Wrong label

1-104 L25 Wrong coTor label

1-105 L25. Wrong color labe 1

1-i06 L26 Inconsistent coloring/labeling of controis

1-107 L26 Inconsistent coloring/labeling of controls

1-108 L26 Inconsistent coloring/labeling of controls

1-109 L27 No labeling and bad orientation

1-110 L27 No labeling and bad orientation

$1-111$ L27 No labeling and bad orientation

T-112 L28 Lack of C/D symmetry

1-113 L28 Lack of C/D symmetry

1-114 L29

$1-175$ L30

Cover sticks open

$1-116$ L30

$1-117$ L31

1-118 L32

Missing label

Missing labe 1

Poor labeling

$1-119$ L32

ESFAS control arrangement.

ESFis contro i arrangement

$1-120$ L32

$1-121$ L 33

$1-122\llcorner 33$

$1-123$ L33

$1-124$ L34

ESFAS control arrangement

Controls poorly located: Too near and similar controls poorly lasated: Too near and similar Controls foorly located: Too near and similar

$1-125$ L34

$1-126 \quad$ L35

$1-127 \quad$ L36

$1-128$ L36

Mirror imaging of controls/displays

Mirror imaging of controls/displays

Poor labeling

Inconsistent abbreriations

$1-129\llcorner 36$

Incons istent abbreriations

$1-130$ L36

Inconsistent abtreyiations

Inconsistent abbreriations 
Insufficient label information

$1-132 \quad\llcorner 37$

Insufficient label information

$1-733\llcorner 38$

control rod full insertien inaicator panel

$1-134 \lcm{639}$

Seperation of identical displays

$1-135<40$

confusing trend recorder/display labeling

$1-136<40$

$1-137<40$

Confusing trend recorder/display labeling

$1-138<41$

Confusing trend recorder/display labeling

$1-139 L 42$

Lack of position labeling

$1-140$ Ł42

Lack of indicator grouping

Lack of indicator grouping

2-1 R1 Inconsistent terminology

2-2 $R 2$ inconsistent terminology

2-3 R3 Incorrect $T-A V E$ and $T$-REF legend

2-4 R4 Inconsistent alarm legend

$2-5$ R5 Inconsistent alarm legend

2-6 R6 Incorrect legend label

$2-7$ R7 Print font too small

2-8 R8 Ho watrix

2-9 R9 Legend does not address spec if ic conditions

2-10 R10 Legend does not address specific conditions

$2-11$ RII Legend does not address specific conditions

2-12 Ri2 No labeling of annunciator controls

2-73 R13 Variabie stroke widths on CRT

2-74 Ri4 Non-functional keyboard

2-15 R15 Phone cord too short

2-16 R15 Phore cord too short

2-17 R16 Keyboard obstructs view of CKT screen

\section{$2-18$ S1 Meter glare}

$2-19 \quad S 2$ Glare on green lighted section

$2-20$ S3 Controls too close to edge

$2-21$ S4 folor coding reversed for ON/OFF on Generex panel

$2-22$ S5 cunling Tower Fan display light legends interchangable

$2-23$ \$6 Controlsidisplays not distinct enough

2-24 57 Foxboro contraliers too similar

2-25 \$7 Foxboro controllers too similar

$2-26 \quad \$ 7$ Foxboro controilers too similar

$2-27$ S8 Key size too small for jog valves

2-28 59 Procedure zart

2-29 S10 control flag can be in opposite position of switch

2-30 511 Switch position indication is not clear

2-31 572 Low energized/de-energized contrast

2-32 513 Mirror inage

2-33 513 Mirror image

2-34 513 Mirror inage

$2-35$ S 14 Lack of labels

2-36 S15 MSIV labels are not properly descriptive 
2-37 S17 Tiles should be on Panel B06

2-38 518 Synchroscope is too far from control

2-39 519 Control knob too close to breaker handle

2-40 S20 Mimic should have label

2-41 S21 Mimic is confusing

242 S22 Circuit breakers not connected to mimic

2-43 S23 Switch too far from nimic

2-44 524 No labels

2-45 S25 Color coding

2-46 S26 Label should read "locked"

2-47 527 Unnecessary redundant meter

2-48 S28 Inconsistent mimic coding

2-49 529 Good diamond setting for mimic flow paths

2-50 \$29 Good diamond setting for mimic flow paths

2-5] S30 Switch position needle does not point to specific positions

2-52 S3\} Inconsistent use of color coding 